\title{
Measures of injury severity in childhood: a critical overview
}

\author{
T F Beattie, C E Currie, J M Williams, P Wright
}

\begin{abstract}
Many different methods for assessing injury severity have appeared in the literature. This paper discusses the commonly used measures, many of which are subjective and depend on clinical practice or sociological factors. Even if apparently objective measures are used their appropriateness for use in children is questionable. Particular problems occur with scoring or categorising events such as poisoning, choking, and near drowning. Researchers need to reach a consensus on injury severity reporting to ensure comparability between studies and programs for injury prevention.

(Injury Prevention 1998;4:228-231)
\end{abstract}

Keywords: injury severity; severity scoring

As the literature expands on childhood injury it is evident that different authors are using different end points to describe the success or failure of various injury prevention programmes. Similarly, surveillance exercises often classify injury in terms of the aetiology (for example burn injury, fall) or in broad categories of injuries sustained (for example head injury, fracture) without reference to any objective severity measure..$^{1-5}$

A plea has previously been made for a more standardised, uniform reporting of childhood injury. ${ }^{6}$ This paper aims to emphasise both the importance of injury severity and the importance of defining injury severity markers to ensure standardisation of reporting. Currently used severity measures and proxies for severity are discussed and methods suggested as to how measurement could be improved.

\section{General, non-specific measures used as markers of severity}

MORTALITY

Mortality is a well defined and fixed end point but does it reflect the severity of the actual injury or measure the quality of medical care? Certainly, after trauma, children have been shown to die as a result of suboptimal medical care. ${ }^{7}$ For any given injury severity mortality, in areas where medical provision is poor, will be worse than where medical care is optimal. ${ }^{89}$
Thus mortality may be as much a marker of the quality of medical care as it is of injury severity.

HOSPITAL ADMISSION

Hospital admission has commonly been used as an indicator of severity of injury. ${ }^{10}$ Indeed, Davidson et al state that it is the only worthwhile measure of severity. Those not admitted are often in the minor, insignificant category. ${ }^{11}$ This, however, is probably an extreme view. Only a minority of all injured children are admitted to hospital. ${ }^{12}$ As long as clinical practice remains constant over time and the same categories of children are admitted, then admission to hospital can be taken as a reliable marker of severity. However clinical practice changes, both with advances in technology, and with more information regarding processes. Head injury is a good example of how clinical practice and changes in technology merge to alter admission rates. Before the advent of regularly available computed tomography, children who had suffered a head injury underwent skull radiography and were admitted for periods of observation. Recent evidence suggests, however, that children who have little chance of brain lesion or intracranial injury may be allowed home if an initial computed tomogram is normal. ${ }^{13}$ Attendance figures at accident and emergency departments, or the rate of injury, may remain the same but admission figures will be radically altered by this change in policy. The management of injury is also, in part, a function of hospital policy. Hospitals have different criteria for admitting injured children. For example, a burn injury is managed according to surface area, depth, and site of the burn, together with any potential complications, such as hypothermia or toxic shock syndrome.

Accidental paracetamol (acetaminophen) poisoning is managed differently depending on local facilities. Some departments will admit children after they have received initial gastric decontamination and wait for the child to have four hour paracetamol concentrations measured on a hospital ward. The child may then be sent home after the results are available but this child will have been "admitted" and will appear on inpatient statistics. Other departments will keep the child in the accident and emergency department until the paracetamol concentrations are available, and then discharge the child 
Table 1 Example of the abbreviated injury score (AIS) (for a fuller description see the 1990 revision of the $A I S^{25}$ )

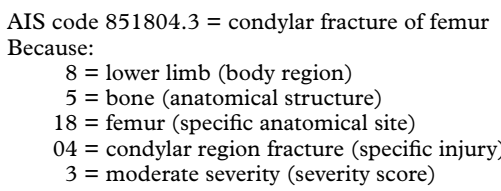

if the levels are in a non-toxic range. These latter children will not feature in inpatient statistics.

Similarly, departments that can and do treat all wounds or manipulate fractures within the accident and emergency setting and discharge children afterwards will have a lower admission rate than departments that require children to be admitted for these procedures. ${ }^{14}$ Not all children's fractures require manipulation and these will never appear on inpatient statistics. With any injury, children from poor home circumstances are more likely to be admitted, especially if there is no ready access to transport. From the foregoing it can be seen that admission alone is an unreliable measure of severity for many childhood injuries. It depends on the nature of the injury, the services available in any given hospital, and the clinical preferences of the physicians.

\section{ATTENDANCE AT THE ACCIDENT AND}

EMERGENCY DEPARTMENT

Attendance at a hospital accident and emergency department has been used to define the incidence of injury in childhood. ${ }^{5}{ }^{15}{ }^{16}$ It is also used as a proxy measure of injury severity. There are several problems, however, with doing so.

First, there is the problem of access. Children distant from a major accident and emergency department are less likely to present to the hospital for treatment. ${ }^{17}$ These children are more likely to receive their care for less severe injury in a local setting or from their parents, and only present to hospital if the injury cannot be dealt with safely in the community. Similarly, advice may be given over the telephone to avoid hospital attendance. ${ }^{18}$

The decision to attend hospital will also depend on local practice. Many schools have a policy of taking children who have been injured while under school supervision to the local accident and emergency department "just in case". This may be more common in urban rather than rural populations. Another cause for accident and emergency attendance, living close to a grandmother, has recently been reported. ${ }^{19}$

There is little research on the socioeconomic demographics of attendance at emergency departments, but what there is suggests deprivation increases emergency department use. ${ }^{2021}$ Using attendance at hospital may be more a marker of social circumstances than actual injury severity, but is, nevertheless useful when analysing injury trends within a community.

TIME OFF SCHOOL

"Time off school" has also been used as a severity measure. ${ }^{316}$ Clearly many children will be "off school" because the injury necessitates a hospital stay or convalescence at home. Alternatively, children may be "off school" for reasons that have nothing to do with the actual injury sustained and more to do with social factors and attitudes. Children on crutches may be unable to use stairs in school or those with upper limb fracture casts may find aspects of personal hygiene difficult. Parents may elect to keep children from school because they fear the child may be injured again, particularly if they are using crutches. There is still a widespread notion among many people that injury equates to illness, and this, by definition, warrants the child staying away from school until completely better.

\section{SUMMARY}

From the foregoing it can be seen that there are problems with the most commonly used proxy measures of severity after childhood injury, especially when they are used independently. For these reasons, triangulation of such proxy severity measures is recommended, together with the use of formal, objective measures of severity that are the focus of the next section.

\section{Injury specific scoring methods}

Three common instruments have been used in injury scoring: the injury severity score (ISS) ${ }^{22}$; the revised trauma score (RTS) ${ }^{23}$; and the paediatric trauma score (PTS).$^{24}$ Of these, the PTS is the only one specifically designed for children.

Table 2 Typical injury severity score (ISS) calculation in a $20 \mathrm{~kg}$ child with injuries sustained in fall from tree

\begin{tabular}{|c|c|c|c|c|}
\hline $\begin{array}{l}\text { ISS body region } \\
\text { (column 1) }\end{array}$ & Injury (column 2) & $\begin{array}{l}\text { AIS code }+ \text { score } \\
\text { (column 3) }\end{array}$ & $\begin{array}{l}\text { Highest AIS in body } \\
\text { region (column 4) }\end{array}$ & AIS $S^{2}$ (column 5) \\
\hline \multirow[t]{3}{*}{ Head/neck } & Fracture vault of skull & $150400-2$ & & \\
\hline & Loss of consciousness for $3 \mathrm{~min}$ & $160202-2$ & & \\
\hline & Cerebral contusion & $140602-3^{\star}$ & 3 & $9\left(3^{2}\right)$ \\
\hline Face & Bruised cheek & $210402-1^{\star}$ & 1 & \\
\hline Chest & No injury & - & & \\
\hline Abdomen & Bruised abdominal wall & $510402-1^{\star}$ & 1 & \\
\hline \multirow[t]{3}{*}{ Extremities } & Fracture ulna closed & $753202-2^{\star}$ & & \\
\hline & Fracture radius closed & $752802-2^{\star}$ & 2 & $4\left(2^{2}\right)$ \\
\hline & Knee sprain & $750826-2^{\star} \star$ & & \\
\hline External & Abrasions & $910200-1^{\star}$ & 1 & $\begin{array}{l}1\left(1^{1}\right) \\
\text { ISS }=14(1+4+9)\end{array}$ \\
\hline
\end{tabular}

^ In column 3 the bold numbers are the highest abbreviated injury score (AIS) coded in each region. The three body regions with the highest scores are chosen (column 4); these AIS code values are then squared (column 5) and then summed to give the ISS. Note: it would be acceptable to use values for "abdomen" or "face" in place of "external". 
Table 3 The same $20 \mathrm{~kg}$ child as in table 2 who has presented with a blood pressure of 90/60 $\mathrm{mm} \mathrm{Hg}$ (coded as 4), respiratory rate of 37 breaths/min (coded as 3), and a Glasgow coma scale of 11 (coded as 3). The revised trauma score is 10 (sum of coded values)

\begin{tabular}{llllll}
\hline Coded value & 4 & 3 & 2 & 1 & 0 \\
Glasgow coma scale & $13-15$ & $9-12$ & $6-8$ & $4-5$ & 3 \\
Systolic blood pressure (mm Hg) & $>89$ & $76-89$ & $50-75$ & $1-49$ & 0 \\
Respiratory rate (breaths/min) & $10-29$ & $>29$ & $6-9$ & $1-5$ & 0
\end{tabular}

Table 4 Paediatric trauma score ${ }^{24}$

\begin{tabular}{llll}
\hline & +2 & +1 & -1 \\
\hline Weight $(\mathrm{kg})$ & $>20$ & $11-20$ & $\leqslant 10$ \\
Systolic blood pressure $(\mathrm{mm} \mathrm{Hg})$ & $>90$ & $50-90$ & $<50$ \\
Level of consciousness & Normal & Obtunded or LOC & Comatose \\
Airway & Normal & Maintainable & Unmaintainable \\
Wound & None & Minor & Major or complicated \\
Fracture & None & Single & Open or multiple \\
\hline
\end{tabular}

^Loss of consciousness.

INJURY SEVERITY SCORE

This is an index based on the severity of anatomical injury sustained. It is derived from a large database of injuries, and is based on the abbreviated injury score (AIS). ${ }^{25}$ This has two components: (1) a unique six digit number that codes the body region of the injury, the structure involved, and the type of injury sustained and (2) a suffix that codes for the severity of the injury, graded 1-6, with 1 indicating a minor injury while 6 is incompatible with life (table 1).

The ISS is calculated from combinations of the AIS. The body is divided into six areas: head and neck; face; thorax including dorsal spine; abdomen (including lumbar spine and pelvic contents); limb injury (upper and lower limb); and external (including skin and burns). Every injury is identified, and the most severe in each of these areas is identified. Subsequently, the three worst affected areas are determined. The ISS is the sum of the squares of these injuries, ranging from 1-75. By convention, a score of $1-8$ is considered minor injury, 9-16 is moderate, and above 16 severe. An ISS >41 indicates very severe injury with very significant mortality (see table 2 ).

Another method of injury scoring, again based on the AIS, is to take the maximum abbreviated injury score (MAIS). ${ }^{26}$ This ignores the effect of multiple injury but, as many children only suffer one injury, this is probably acceptable. The MAIS is based on the single most severe injury sustained and is always a score between 1 and 6 . In table 2 , the most severe injury is cerebral contusion, with an AIS of 3, therefore MAIS will be 3 .

The ISS, AIS, and MAIS only apply to physical injury and are not intended for assessing events such as drowning, poisoning, or choking. Additionally, these measures are not "child friendly" and are derived substantially

Table 5 Paediatric trauma score (PTS) for the same $20 \mathrm{~kg}$ child whose injuries are described in table 2

\begin{tabular}{lll}
\hline Weight (kg) & 20 & +2 \\
Systolic blood pressure (mm Hg) & 90 & +2 \\
Level of consciousness & Lost consciousness & +1 \\
Airway & Normal & +2 \\
Wound & Minor abrasions & +1 \\
Fracture & Multiple & -1 \\
& & PTS $=7$ \\
\hline
\end{tabular}

from adult norms. No allowance is made, for instance, for a child's bone structure and its ability to remodel. Child head injuries are also poorly dealt with, particularly when used in settings where computed tomography is not widely available.

\section{REVISED TRAUMA SCORE}

The RTS is a physiological measure of the wellbeing of an individual who has sustained an injury. As the name suggests, it is primarily used to determine injury after a traumatic event and is not intended for use with poisoning, choking, etc. It relies on three components: (1) the Glasgow coma scale; (2) systolic blood pressure; and (3) respiratory rate.

Table 3 illustrates the scores for a child sustaining moderate trauma with a low chance of death. It matches well with MAIS $=3$ and ISS $=14$, both of which have similar expected outcomes.

As with the AIS, adult norms have been used to derive the parameters of this scale, and there are no paediatric adaptations of the RTS. For instance, the Glasgow coma scale is difficult to use on children under 5 years of age. Children can have blood pressures that are below the lowest threshold in the adult, and still be "normal"; similarly as the respiratory rate changes (falls) with age adult norms cannot be extrapolated to children. Although there are correcting factors for blunt and penetrating trauma, there are none to allow for the generally better prognosis for children with any given physiological insult. In general, this score is poorly applicable to children.

\section{PAEDIATRIC TRAUMA SCORE}

This relies on a six point score, validated against a large paediatric database, but again only for physical trauma. Weight, systolic blood pressure, ability to maintain an airway, level of consciousness, presence of fracture, and presence of a wound are each scored as either $+2,+1$ or -1 (best to worst) depending on the severity. The sums are then added producing a score that ranges from +12 to -6 . A score 9-12 indicates minor injury and there should be no mortality; a score $<0$ indicates severe trauma with high mortality. Score $0-8$ indicates severe to moderate injury with associated decreasing mortality (see table 4). For example, the injuries described in table 2 can be converted to the PTS (see table 5). This is a useful score, particularly for physical injury, but will not score poisoning particularly well.

\section{Conclusion}

This review of the measures commonly found in the literature on childhood injury, while not exhaustive, indicates that there is no entirely acceptable way to determine the severity of an injury in any given child. There is need for a consensus as to the method of reporting childhood injury severity to enable comparisons to be made.

Scoring is probably easier where injuries are due to physical trauma. There is little in the way of objective scoring for non-traumatic 
events, such as poisoning, choking, inhalation, thermal injury, or near drowning. These injury events often tend to either result in discharge from the accident and emergency department, near misses, or death. Their significance will be underestimated if severity is measured in terms of hospital admission or attendance at accident and emergency. Admission to hospital, as we have demonstrated, is a poor proxy because of the large number of variables that can influence it. More discussion is needed to achieve consensus on measures effective in reporting severity of injury after these non-traumatic events.

Wherever possible, objective measures of injury scoring should be included in any paper submitted to a scientific journal. Only when an agreed method is followed can others repeat the study, either in the same country, or in another, decide whether they are dealing with the same problem amenable to similar prevention strategies.

1 Singer G, Freedman LS. Injuries sustained on "bouncy castles". BMF 1992;304:912.

2 Cass DT, Ross F, Lam L. School bus related deaths and injuries in New South Wales. Med f Aust 1996;165:137-7.

3 Lee AJ, Garraway WM. Epidemiologic comparisons of injuries in school and senior club rugby. Br F Sports Med 1996; 30:213-17.

4 Smith GA, Dietrich AM, Garcia CT, et al. Epidemiology of shopping cart related injuries to children. An analysis of nhopping cart related injuries to children. An analysis of 1995;149:1207-10.

5 Couper RT, Monkhouse W, Busutil M, et al. Stroller safety. Med F Aust 1994;160:335-8.

6 Christoffel KK, Scheidt PC, Agran PF, et al. Standard definitions for childhood injury research: exerpts of a conference report. Pediatrics 1992;89(6 pt):1027-34

7 Sharples PM, Storey A, Aynsley-Green A, et al. Avoidable factors contributing to death of children with head injury. BMF 1990;300:87-91

8 Cooper A, Barlow B, DiScala C, et al. Efficacy of pediatric trauma care: results of a population-based study. 7 Pediat Surg 1993;28:299-303.
9 Haller JA, Beaver B. A model: systems management of life threatening injuries in children for the State of Maryland, USA. Intensive Care Medicine Supplement 1989;1:S53-6.

10 Smith T. Accidents, poisoning and violence as a cause of hospital admissions in children. Health Bull (Edinb) 1991;49:237-44.

11 Davidson LL, Durkin AS, O'Connor P, et al. The epidemiology of severe injuries to children in northern Manhattan: methods and incidence rates. Paediatr Perinat Epidemiol methods and inci

12 Carter YH, Jones PW. Accidents among children under 5 years old: a general practice based study in North Staffordshire. Br f Gen Pract 1993;43:159-63.

13 Masters SJ, McClean PM, Arcarese JS, et al. Skull X-rays after head trauma: recommendations by a multidisciplinary panel and validation study. N Engl f Med 1987;316:84-91.

14 Blasier RD, White R. Intravenous regional anesthesia for management of children's fractures in the emergency department. Pediatr Emerg Care 1996;12:404-6.

$15 \mathrm{Hu}$ X, Wessen D, Kenney B. Home injuries to children. Can f Public Health 1993;84:15-8.

16 Currie CE, Williams JM, Wright $\mathrm{P}$, et al. Incidence and distribution of injury among schoolchildren aged 11-15. Inj Prev 1996;2:21-5.

17 McClure R. Injury and general practice in Australia. Aust Fam Physician 1995;24:2059-63.

18 Kernohan SM, Moir PA, Beattie TF. Telephone calls to a paediatric accident and emergency department. Health Bull (Edinb) 1992;50:233-6.

19 Ellen JM, Ott MA, Schwarz DF. The relationship between grandmothers' involvement in child care and emergency department utilization. Pediatr Emerg Care 1995;11:223-5.

20 Ben-Shlomo Y, White T, McKeigue PM. Prediction of general practice work load from census based social deprivation scores. F Epidemiol Community Health 1992;46:532-6.

21 Yamamoto LG, Zimmerman KR, Butts RJ, et al. Characteristics of frequent emergency department users. Pediatr Emerg Care 1995;11:340-6.

22 Baker SP, O'Neill B, Haddon W, et al. The injury severity score: a method for describing patients with multiple injuries and evaluating emergency care. $\mathcal{F}$ Trauma 1974;14: $187-96$.

23 Champion HR, Sacco WJ, Copes WE, et al. A revision of the trauma score. F Trauma 1990;30:539-46.

24 Tepas JJ, Mollit DC, Talbert JL, et al. The pediatric trauma score as a predictor of injury in the injured child. $\mathcal{F}$ Pediatr Surg 1987;22:14-18.

25 Association for the Advancement of Automotive Medicine. The abbreviated injury scale 1990 revision. Des Plaines, IL: AAAM, 1990

26 Ruta D, Beattie TF, Narayan V. Prospective study of non-fatal childhood road traffic accidents: what can seat belt restraint achieve? F Public Health Med 1993;15:88-92. 